\title{
Explorative Spatial Analysis of Neandertal Stes using Terrain Analysis and Stochastic Environmental Modelling
}

GI_Forum 2018, Issue 2

Page: 21 - 38

Full Paper

Corresponding Author:

michael.maerker@unipv.it

DOI: 10.1553/giscience2018_02_s21

\author{
Michael Märker1,2 and Michael Bolus² \\ IUniversity of Pavia, Italy \\ 2Heid elberg Ac ademy of Sc iences and Humanities, Gemany
}

\begin{abstract}
In this paper we present a unique spatial da taset of Neandertal sites in Europe. Information on topographic locations with human fossils was collected in the course of our own work and from a comprehensive literature review. The fossils are classified into Pre-Neandertals, Early Neandertals and Classic Neandertals. Based on this dataset, we explored the environmentally constrained site-selection criteria of Neandertals. The site locations are described by topographic indices giving infomation on climatic, strategic and waterrelated criteria on which Neandertals may have based their site selection. We applied two different explorative statistical approaches for the three Neandertal fossil classes, deriving robust and consistent results for Early and Classic Neandertals. However, because of the nature and size of the response variables showing a certain heterogeneity and due to landscape dynamics, which might have occurred in the observed periods, we focus on the overall trends that the data show. The study reveals that Early and Classic Neandertals not only show specific spatial distributions but are also characterized by different environmental preferences. Both models reproduce the particular site preferences for Early and Classic Neandertals, which demonstrate a higher relevance of climatic issues for the Early Neandertals and a pronounced strategic component for the Classic Neandertals. Additionally, the methodology a llows for a spatial prognosis of occurrence probabilities for Neandertal sites. Extemal va lidation using a spatial artefact da taset for the German Middle Paleolithic shows generally good a greement.
\end{abstract}

\section{Keywords:}

explora tive data analysis, Neandertal sites, terra in analysis, boosted regression trees, maximum entropy

\section{Introduction}

Based on the present fossil evidence, the Neandertals were an indigenous European hominin whose origins can be seen exclusively on this continent. They probably evolved out of late forms of Homo heidelbergensis or archaic Homo sapiens (see, e.g., Hublin, 1998; Rightmire, 1998; Bräuer, 2008). The earliest fossils with diagnostic Neandertal traits and thus belonging to the Neandertal lineage may date back almost $450 \mathrm{ka}$ (fossils from Sima de los Huesos in 
Atapuerca, Spain: Arsuaga et al., 2014). During a process that might be called 'neandertalization', which can be described using an 'accretion model' (see, e.g., Dean et al., 1998; Hublin, 1998; Harvati, 2007), more and more Neandertal traits accumulated, until the Classic Neandertals appeared, during the last glaciation. Following this model, the fossils considered in this paper have been classified into three categories (see also Serangeli \& Bolus, 2008):

1. Pre-Neandertals are fossils of Homo beidelbergensis or archaic Homo sapiens which yield the first distinct Neandertal features and thus, though not being Neandertals themselves, stand at the threshold of what might be referred to as Neandertals.

2. Early Neandertals, appearing around $200 \mathrm{ka}$ ago or most probably somewhat earlier (during MIS 7; see, e.g., Hublin, 2007), can be distinguished clearly from Homo beidelbergensis. In this paper, the term Early Neandertals is used for all preWeichselian/Wurmian Neandertal fossils.

3. Classic Neandertals appear with the last ice age, ca. $115 \mathrm{ka}$ ago (MIS 5d). Among the best known and studied is the type specimen discovered in the Neander Valley, Germany, in 1856. Fossils of Classic Neandertals are spread over large parts of Europe and beyond.

All European sites with Neandertal fossils discussed in the literature (to July 2017) were considered in the present study. The sample comprises 189 sites, including 11 sites with PreNeandertals, 32 sites with Early Neandertals, and 146 sites with Classic Neandertals. The total number of sites, including non-European ones, was 219 from 29 countries, including 11 with Pre-Neandertals, 34 with Early Neandertals, and 174 with Classic Neandertals (Serangeli \& Bolus, 2008).

A map showing all sites with Neandertal fossils known from the literature highlights the core area of Neandertals in southern and southwestern Europe (Figure 1). Given this core area, Neandertals originally were adapted to a temperate climate, rather than a cold or even extremely cold one. However, under more favorable climatic and environmental conditions, they repeatedly left their core area to move temporarily or permanently into other areas, and even adapted to cope with harsher environmental and climatic conditions. During the last ice age, Classic Neandertals enlarged their originally exclusive European settlement area, expanding into the Near East, parts of Central Asia, and as far as the Altai region of Siberia, a dispersal that has been called the 'Out of Europe Movement' of Neandertals (Serangeli \& Bolus, 2008; Bolus, 2014). 


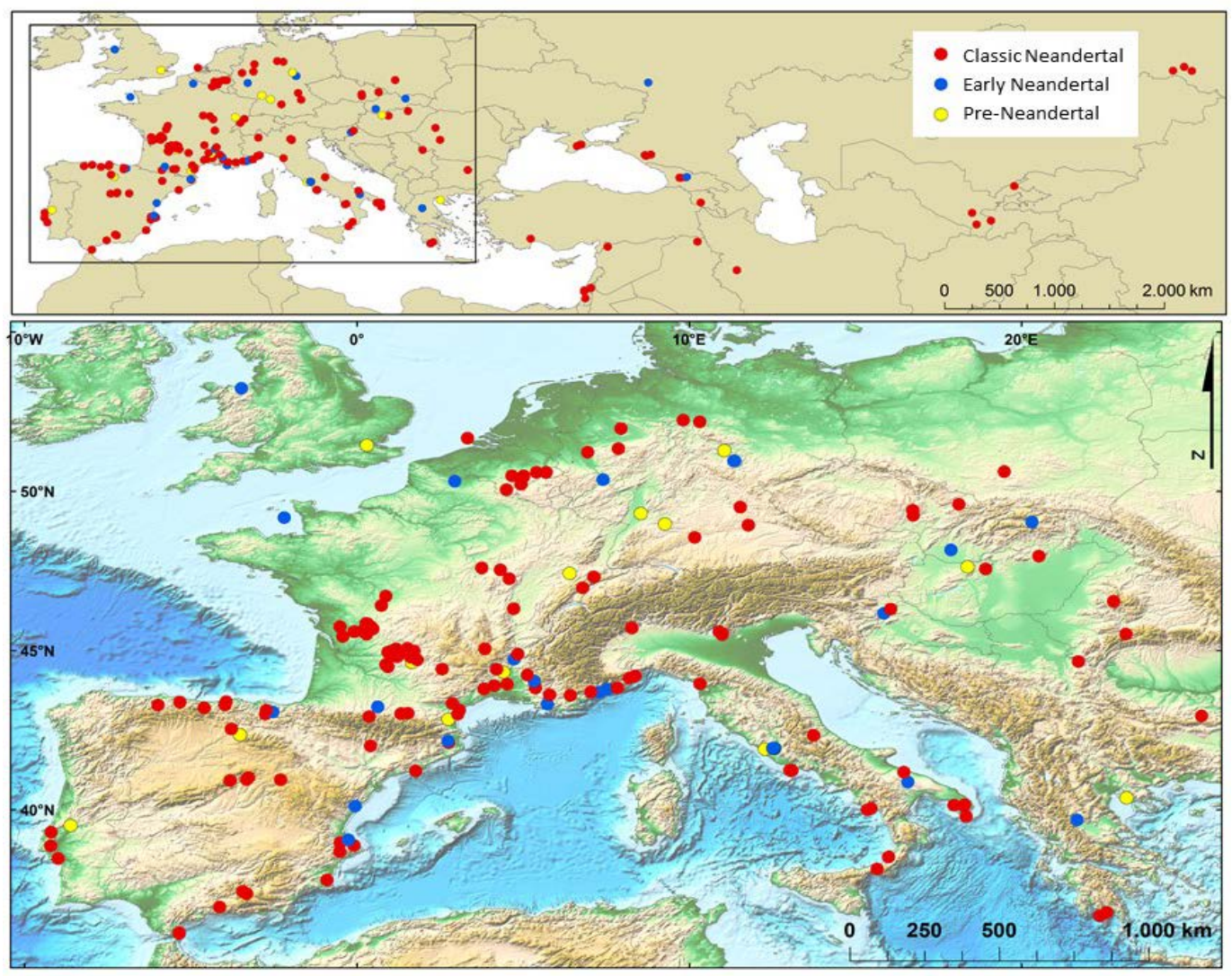

Figure 1: Distribution of sites with Neandertal fossils (red = Classic Neandertals; blue =Early Neandertals; yellow = Pre-Neandertals)

Neandertal expansions, expansion corridors and settlement areas might have followed specific spatial patterns. In this study, we follow the hypothesis that the expansion corridors and settlement sites are controlled by environmental driving factors. Hence, analysing the known settlement locations for the three Neandertal classes with regard to environmental factors, we might be able to decipher specific preferences for site locations. Moreover, we can use this knowledge to explore potential site locations on broader spatial scales. In this study, the environmental characteristics of the site locations are described by topographic indices derived from a digital elevation model (DEM), giving information on climatic, strategic and water-related criteria that Neandertals may have based their site-selection on.

\section{Materials and Methods}

To analyse the functional relationship between spatial datasets of driving factors and response variables, we use the Neandertal site classes as the dependent response variables in the model application. Different topographic indices were derived to analyse the possible 
combinations of factors describing particular site characteristics related to the specific Neandertal classes. We tested two different explorative statistical models: (i) a classification regression tree approach and (ii) a mechanical statistics method. The application of two models with the same dataset guarantees consistent and robust modelling results. However, due to the nature and size of the response variables, which showed a certain heterogeneity, and due to landscape dynamics, which might have occurred in the observed periods, we do not perform a sophisticated stochastic analysis but explore the trends that the data show.

Both approaches employ a learning algorithm to identify the model that best fits the relationship between the attribute set (environmental variables) and the response variable, which in this case is the class of Neandertals. The hypothesis behind the approaches can be summarized as follows:

(i) We can derive different environmental proxies describing hydrology, geomorphology, vegetation, soils and climate as well as strategic issues directly from the topography. Moreover, information about the related process dynamics can also be deduced from the topography.

(ii) Regional topographic elements are quite conservative, meaning that the present-day topography reflects elements and processes of paleo-landscapes, at least if the spatial resolution is not too high (e.g. Velichko \& Spasskaya, 2017; Vogel and Maerker, 2015; Goudie 2004). For this study, we selected a cell size of $6,25 \mathrm{ha}$ (pixel size $=250 \mathrm{~m} \times 250 \mathrm{~m}$ ). A higher resolution generally shows an increased level of local noise and artefacts (e.g. infrastructures; vegetation); at coarser scales, the information loss is too great. The chosen cell size is thus a compromise between too much local error and enough detail to characterize the major landscape patterns and processes. Moreover, the results of the stochastic models at the chosen cell size are more robust against localization errors of the Neandertal sites.

Present-day topography can be utilized to detect relations between site locations and their environmental surroundings. Therefore, we selected two stochastic modelling approaches that are well established in a variety of scientific disciplines such as soil mapping (e.g. Minasny \& McBradney, 2016), landscape reconstruction (e.g. Vogel \& Märker, 2010), geomorphic processes assessment (e.g. Vorpahl et al., 2012), or species distribution modelling (e.g. Gomes et al., 2018).

The first model combines a classification and regression tree approach with a gradientboosting algorithm (Elith et al., 2008), also known as boosted regression tree (BRT) (Friedman 2001). Multiple simple classification trees are grown successively, each new tree being used to improve the predictions of its predecessor. Only the first tree is estimated on the training data; all successive trees are grown on the residuals of the preceding tree (Vorpahl et al., 2012).

BRT presents various advantages: (i) it is not sensitive to data errors in the input variables; (ii) automatic variable subset selection; (iii) it can handle data without pre-processing; (iv) resistance to outliers; (v) automatic handling of missing values; (vi) robustness to dirty, partially inaccurate data; (vii) high speed, and (viii) resistance to over-fitting (Friedman, 1999, 2001). These strengths have strategic advantages, especially when dealing with site locations 
that cannot be identified with high topographic accuracy. Once the environmental relations of the Neandertal site locations are derived, these can be assessed and differences in the environmental preferences between the Pre-, Early and Classic Neandertals can be detected.

The second modelling approach originates in Bayesian statistics (Jaynes, 1957) and is called the Maximum Entropy Method (MEM). MEM estimates a distribution function of the predictors by finding a distribution of maximum entropy for the single predictor that is closest to uniform (Vorpahl et al., 2012). Furthermore, the expected value of each predictor under the estimated distribution has to match its empirical average (Phillips et al., 2004). The advantage of MEM is that it can handle presence-only data, and so does not need classified variables or a binary presence-absence dataset. Our dataset consists of classified Neandertal fossil locations that can be attributed to Pre-, Early and Classic Neandertals; the fossils are evidence of Neandertals' presence at the sites in question. However, the absence of a species (e.g. Neandertals) from a certain location is difficult to prove (Phillips, Anderson \& Schapire, 2004; Phillips, Dudík \& Schapire, 2006). Using MEM, Neandertal classes can be modelled separately without an absence control group. In our case the MEM model was applied using version 3.3.3k of the free 'MaxEnt' software (Phillips et al., 2004; Phillips \& Dudík, 2008).

Finally, the models can be utilized to regionalize the probabilities of the spatial distribution of Neandertal site locations for the whole of Europe. The methodologies allow for an assessment of large areas, and hence significantly improve the understanding of environmental factors in determining site locations.

\section{Model validation method}

Although our data analysis was explorative in nature, a quantitative evaluation of the model's performance was carried out. The ability of the model to classify the types of Neandertal fossil sites was evaluated by simple measures of model performance for both training and test data. The test run was carried out using an internal 10-fold cross-validation procedure (Grimm et al. 2008), for which we applied two performance measures: sensitivity (Sn) and specificity (Sp). $\mathrm{Sn}$ is the proportion of observed presences that had been predicted as such, while $\mathrm{Sp}$ is the proportion of negative cases correctly predicted. The models' predictive performance was assessed by constructing the Receiver Operating Characteristics (ROC) curves for each Neandertal class, for both the training and the test data (Fielding \& Bell, 1997; Phillips \& Elith, 2010). In a ROC curve, the Sensitivity is plotted over the False Positive Rate (1-Specificity) for all possible cut-off points (Swets, 1988). The quality of a ROC curve is quantified by the area under the ROC curve (AUC) (Hanley \& McNeil, 1982). The AUC was shown to be independent of prevalence (Manel et al., 2001); it is considered a highly effective measure for the performance of ordinal score models. A perfect discrimination between positives and negatives has a ROC plot that passes through the upper left corner (100\% sensitivity, $100 \%$ specificity), so that the AUC is equal to 1 (Reineking \& Schröder, 2006). According to Hosmer and Lemeshow (2000), AUC values exceeding 0.6 / $0.7 / 0.8 / 0.9$ indicate poor / acceptable / excellent / outstanding predictions. 


\section{Model input data}

The dependent variable or target variable in this study are the site locations of the three Neandertal fossil classes, described by latitude and longitude. The information on the site locations was collected from the literature and our own research. Since the spatial characterization of the classified Neandertal sites depends crucially on the sites' spatial accuracy, considerable effort was made to correct the data by a twofold approach: (i) we checked and transformed the coordinates to the same projection (Universal Transverse Mercator, WGS84); (ii) all sites were checked for site accuracy using high-resolution maps and Google-Earth. Thus, we reduced the error for spatial accuracy to a minimum.

The dataset consists of a total of 184 Neandertal sites with human remains in Europe (Ntot = 184). Figure 1 illustrates the spatial distribution of these Pre- $($ Npre $=10)$, Early $($ Nearly $=$ $31)$, and Classic Neandertal sites (Nclassic $=143)$.

For the external model validation, we used 139 sites in Germany with Middle Paleolithic artefacts but without Neandertal fossils. By analogy with the sites with Neandertal fossils, we defined three classes for the sites with artefacts: (1) Late Early Paleolithic/Early Middle Paleolithic sites dating to MIS 11 - MIS 8 (ca. 425-240 ka: 16 sites), corresponding to the Pre-Neandertal fossil sites. All are open-air sites. (2) Middle Paleolithic sites dating to MIS 7 - MIS 5e (ca. 240-115 ka: 27 sites), corresponding to the Early Neandertal fossil sites. 26 of the sites are open-air sites; only one is a cave site. (3) Middle Paleolithic/Late Middle Paleolithic sites dating to MIS 5d - MIS 3 (ca. 115-30 ka: 96 sites), corresponding to the Classic Neandertal fossil sites. 51 are open-air sites, and 45 are cave or rock shelter sites.

The independent variables used to model and predict the environmental characteristics of Neandertal sites consist of 61 topographic indices identified using a DEM with 250m resolution. The DEM is based on a Shuttle Radar Topographic Mission (SRTM) elevation model with $90 \mathrm{~m}$ resolution. The SRTM images were merged and pre-processed in order to correct and eliminate construction errors and man-made artefacts (Olaya and Conrad, 2008). The DEM was then resampled to $250 \mathrm{~m}$ resolution and covers large parts of central Europe and North Africa (Figures 4 and 5). The resampling was done in order to minimize the effects of localization errors of sites. Finally, the resampled DEM was hydrologically corrected using a fill-sink procedure following Planchon and Darboux (2001). The algorithm for this guarantees that runoff is routed through the river systems without obstacles, a prerequisite for the application of flow-related algorithms. The derivatives of the DEM can be divided into different groups describing specific site characteristics: (i) climate-related indices, (ii) water-related indices, and (iii) strategic indices. In total, we derived 61 topographic indices using the Terrain Analysis module of the SAGA GIS software package (Böhner et al., 2006; Conrad, 2006). After a first model run, the topographic indices used in the analysis were reduced to 18 .

The water-related indices give information on: (i) the distance to, and reachability of, the next major water course (Horizontal Overland Flow Distance, absolute Distance to River Network, Vertical Distance to River Network, and Drainage Network Base Level), and (ii) the water accumulation or moisture at a certain point in the landscape (Catchment Area, Topographic Wetness Index). The climatic indices comprise: (iii) insolation characteristics 


\section{Märker \& Bolus}

(Aspect, Analytical Hillshading, Direct Insolation, Direct to Diffuse Insolation, Total Insolation, Diurnal Anistropic Heating, and (iv) Wind Effects (Windward and Leeward Effects, Effective Air Flow Height). The strategic aspects are described by: (v) visibility issues (View Distance, Sky View Factor, Maximum Height, Positive Openness, Protection Index, Terrain View Factor), and (vi) indices describing the difficulty of crossing the terrain (Multi-resolution Valley Bottom Flatness, Vector Terrain Ruggedness).

Table 1 lists the topographic indices used and their respective references.

Table 1: Topographic Indices and related references. Blue = water-related indices; Yellow = climatic indices; Green $=$ strategic indices

\begin{tabular}{|c|c|}
\hline Variable & Reference \\
\hline Overland flow distance & Nobre et al., 2011 \\
\hline Catchment area & Freeman, 1991 \\
\hline Channel network base level & Conrad, 2002 \\
\hline Wetness index & Beven and Kirkby, 1979, Moore et al., 1991 \\
\hline Channel network & Nobre et al., 2011 \\
\hline Flow connectivity & Conrad, 2003 \\
\hline Sunset & Böhner and Antonić, 2009 \\
\hline Direct to diffuse ratio & Böhner and Antonić, 2009 \\
\hline Duration of insolation & Böhner and Antonić, 2009 \\
\hline Analytical hillshading & Tarini et al., 2006 \\
\hline Diffuse insolation & Böhner and Antonić, 2009 \\
\hline Diurnal anisotropic heating & Böhner and Conrad, 2008 \\
\hline Windward effect & Böhner and Antonić, 2009 \\
\hline Direct insolation & Böhner and Antonić, 2009 \\
\hline Aspect & Zevenbergen and Thorne, 1987 \\
\hline Leeward effect & Böhner and Antonić, 2009 \\
\hline Maximum height & Marchi and Fontana, 2005 \\
\hline Protection index & Yokoyama et al., 2002 \\
\hline Positive openness & Yokoyama et al., 2002 \\
\hline Negative openness & Yokoyama et al., 2002 \\
\hline Terrain ruggedness index TRI_ & Riley et al., 1999 \\
\hline
\end{tabular}




\section{Results}

The explorative analysis was performed for all three Neandertal fossil classes. However, due to the low number of Pre-Neandertal sites $(\mathrm{NPre}=11)$, the model results for this class are not considered sufficient in terms of robustness and statistical significance. Hence, in what follows we concentrate on the Early $($ NEarly $=32)$ and the Classic Neandertals $(\mathrm{NClassic}=$ 146).

We evaluated the MEM and BRT approaches using the AUC integrals. Figures $2 \mathrm{a}$ and $2 \mathrm{~b}$ show the true positive rate, expressing the sensitivity of the model, plotted against the false positive rate, characterizing the specificity of the model.

As shown in Figure 2a, the performances for the Early and Classic Neandertal fossils using the MEM approach yield good results for the training datasets. Early Neandertal fossil sites show an AUC value of 0.94 and Classic Neandertal fossil sites an AUC value of 0.73. According to the criteria of Hosmer and Lemeshow (2000), this means outstanding (Early Neandertals) and acceptable results (Classic Neandertals). Concerning the test dataset, the performance is poor for both classes, with AUC values of 0.69 (Early Neandertals) and 0.61 (Classic Neandertals).

\section{Early Neandertals}

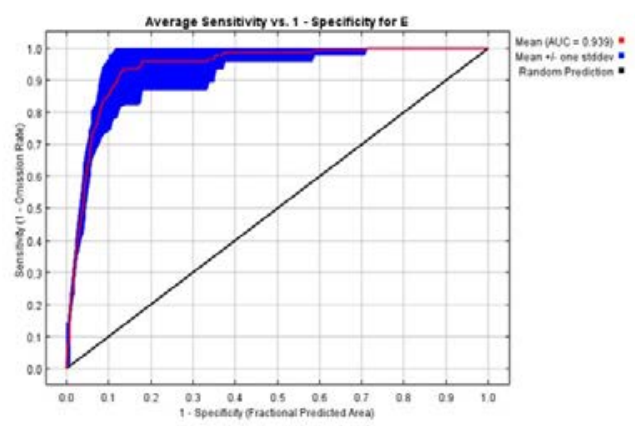

Train AUC $=0.94$

Test $A \cup C=0.69$

\section{Train data Classic Neandertals}

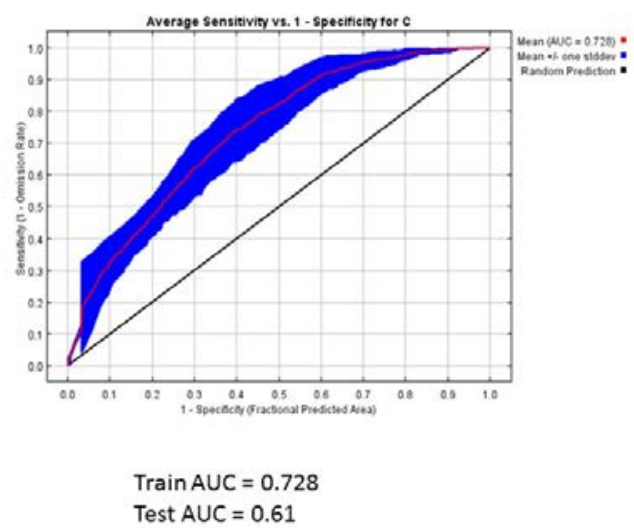

Figure 2a): Receiver Operator Curves (ROC) and Area Under Curve (AUC) integrals for training data sets of Early and Classic Neandertal classes using the MEM approach 


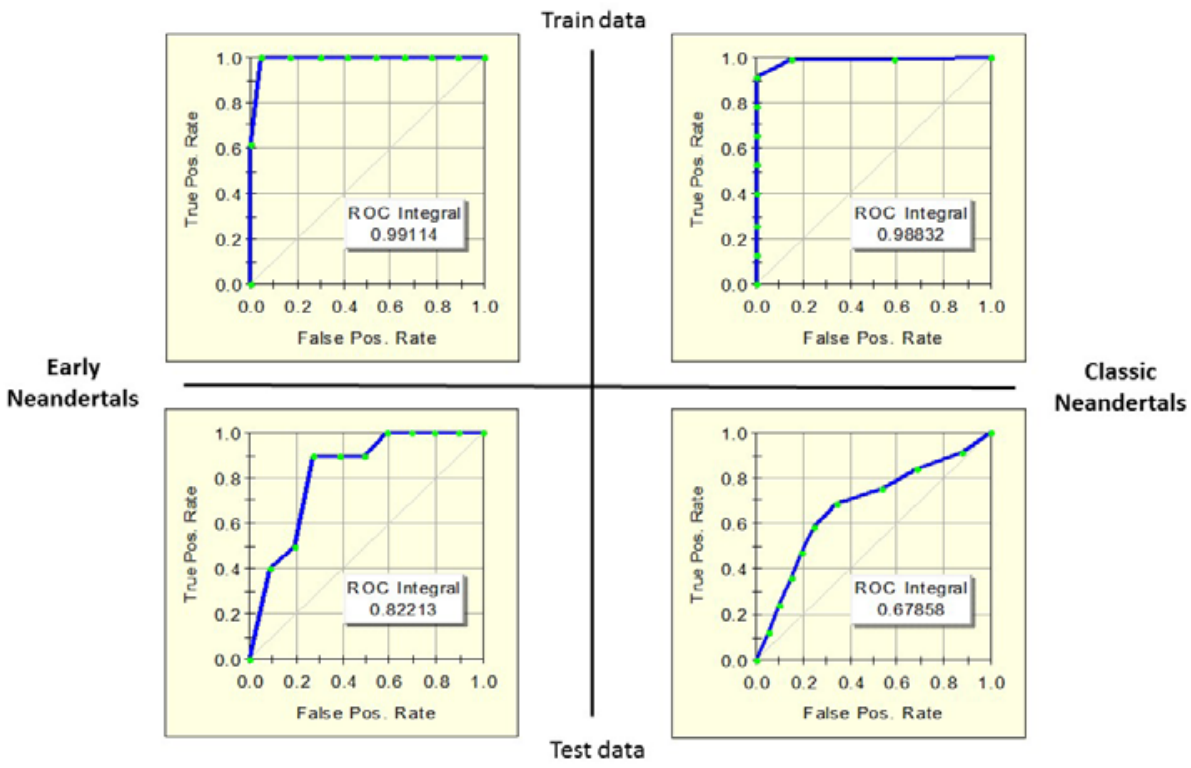

Figure 2b): Receiver Operator Curves (ROC) and Area Under Curve (AUC) integrals for training (above) and test datasets (below) of Early and Classic Neandertal classes using the BRT model

The ROC integrals (AUC) for the BRT model show outstanding performances for the training dataset. The results for the test dataset are excellent in the case of the Early Neandertal sites and nearly acceptable for the Classic Neandertal sites. Generally, the BRT model performs better than the MEM approach.

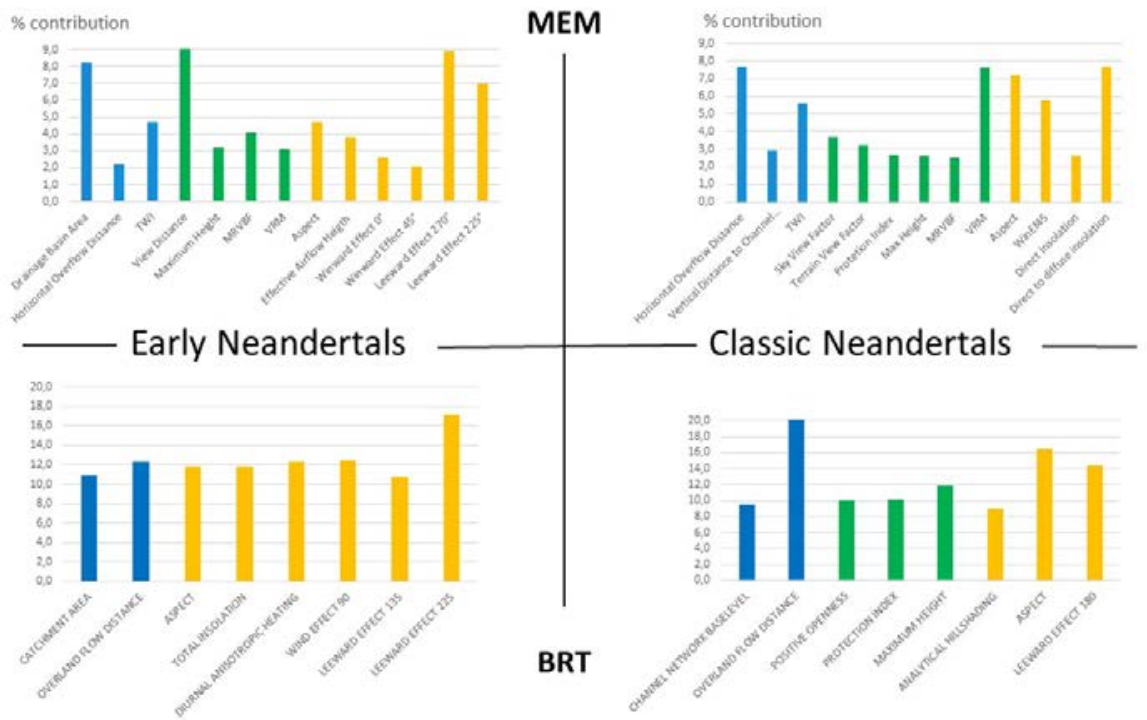

Figure 3: Absolute Variable Importance in \% for Early and Classic Neandertals. Shown are the 18 most important indices 
Figure 3 shows the variable importance for the Early and Classic Neandertal sites. Reported are the most important indices. The variable importance gives significant information on the site preferences of each Neandertal fossil class. As illustrated in Figure 3, the MEM approach shows the occurrence of water-related, climatic and strategic site-selection criteria for the Early and Classic Neandertals. However, a slight dominance of climatic factors controlling site selection can be observed for the Early Neandertal sites, whereas for the Classic Neandertal sites strategic components are more relevant. Generally, the BRT model yields similar patterns, showing that Early Neandertal sites are mainly related to climatic issues, while strategic aspects prevail for Classic Neandertal sites. Strategic aspects seem to be irrelevant for the site selection of Early Neandertals in the BRT modelling.

Based on the model results showing that the BRT approach outperforms MEM, we predicted the spatial probabilities for a specific Neandertal fossil site for the Early and Classic Neandertals, as illustrated in Figures 4 and 5.

In Figures 4 and 5 we report the probabilities higher than $50 \%$ (green for probabilities of 50 $75 \%$, red for probabilities above $75 \%$ ). The prediction was performed for the major part of Europe and parts of North Africa. As shown in Figure 4, the Early Neandertals show lower probabilities than those modelled for the Classic Neandertals (Figure 5). The probabilities for the Early Neandertals show a preference for the larger intra-mountain valleys, as in the Apennines, Extremadura, Massif Central and German Mittelgebirge. However, the flat coastal areas of Benelux, France, Germany and Poland also show probabilities of 50-75\%.

The probabilities for the occurrence of Classic Neandertal fossil sites are generally higher and spatially more widespread than for the Early Neandertals. Probabilities of more than $75 \%$ are reported especially for the steeper areas of mountain ranges such as the Alps, Pyrenees, Sierra Nevada, Northern Apennines, Massif Central and Carpathians. In North Africa, there are some areas with a high potential for Classic Neandertal fossil sites, especially along the coast and in the coastal mountain ranges. Moreover, Mediterranean islands including the Balearics, Corsica and Sardinia illustrate high probabilities, especially in their steeper parts. It should be noted, however, that areas above $2,000 \mathrm{~m}$ are not considered in this study (see Discussion below). 


\section{Märker \& Bolus}

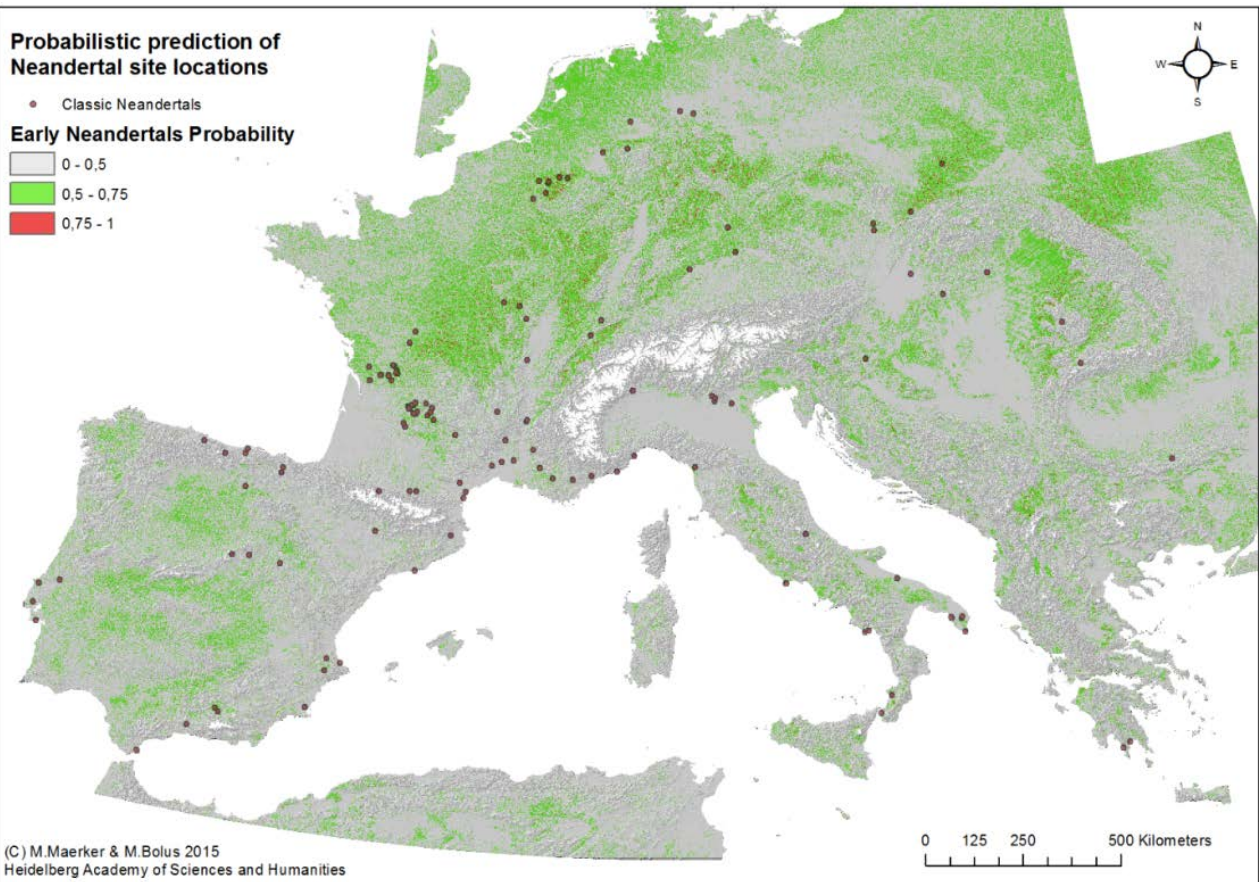

Figure 4: Predicted potential Early-Neandertal find locations. In white: a reas above $2,000 \mathrm{~m}$

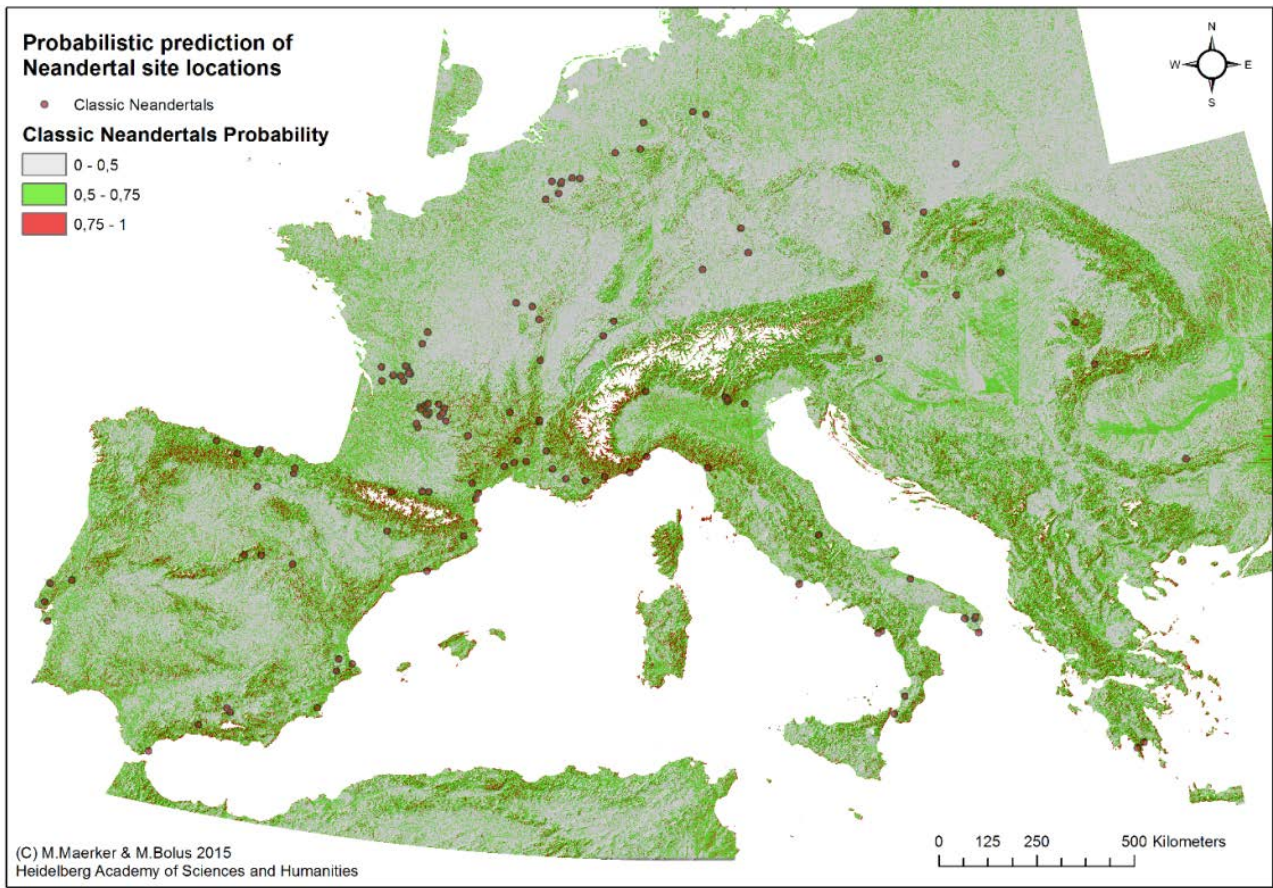

Figure 5: Predicted potential Classic Neandertal find locations. In white: a reas above 2,000m 


\section{Discussion}

The data exploration performed using the BRT and MEM approaches generally explains the relationships between environmental variables and the site locations of the Neandertal classes. The dataset of the Pre-Neandertal fossil sites consists of a very small number of cases $(\mathrm{NPre}=11)$; thus, model performance is low and model reliability generally poor. Consequently, we concentrated on the classes with a higher number of cases $(N e a r l y=32$; Nclassic=146), allowing for more robust and significant interpretations.

The results of the internal model validation generally show a very good model performance for both models concerning the training dataset. If we look more closely at the AUC results of the test datasets, derived using a 10-fold cross-validation procedure, we see that BRT clearly outperforms MEM. This is evidenced not only by the outstanding AUC values for the training data but also, and more importantly, by the acceptable to excellent test data ROC integrals (Hosmer \& Lemeshaw, 2000). Consequently, the results suggest that the Classic and Early Neandertal sites' distributions can be statistically explained using the MEM approach, but model performance is much better using the BRT approach.

The variable importance shows a consistent picture for both models. As the BRT variable importance implies, the Classic Neandertals show a higher differentiation in site-selection criteria, such as water availability (distance to channel network), climatic settings (aspect, leeward effect), and strategic aspects (maximum height, protection index and positive openness). Generally, climatic criteria seem to guide Early Neandertals' site selection, whereas strategic aspects prevail for the Classic Neandertals. Indeed, strategic criteria do not seem to be essential for the Early Neandertal sites, which show a clear preference for climatic characteristics, such as leeward and windward effects, diurnal anisotropic heating and total insolation. However, Early Neandertals, though to a lesser degree, also selected sites with respect to water availability (overland flow distance, catchment area). Generally, both models show significant similarities in site-selection criteria and hence model results can be considered as robust with regard to the following conclusions:

i) Early Neandertals show more climatically-triggered site-selection behaviour;

ii) Strategic aspects prevail for Classic Neandertals;

iii) Water resources play an important role for Early and Classic Neandertals.

The spatial distributions of the site probabilities for the two classes are given in Figures 4 and 5. Due to the better model performance, only the BRT model was utilized to perform a spatial prediction of Neandertal site probabilities.

Regarding the maximum elevation limits of permanent Neandertal sites, debate is still ongoing. In contrast to the probabilistic predictions given in Figures 4 and 5 for Early and Classic Neandertals, only very few Middle Paleolithic sites at high altitudes have in fact been found. This is valid even if one considers sites with Middle Paleolithic artefacts only.

In the Eurasian context, the highest altitudes for sites with Pre-Neandertal fossils are in the Sima de los Huesos and Galeria sites in Atapuerca (Spain) (Rodríguez et al., 2011), which are situated at just over $1,000 \mathrm{~m}$. The highest-altitude sites with Classic Neandertal fossils are also 
in Spain (e.g. Horá: Martín \& Rodríguez, 1979), at ca. 1,200m; in Iran (Bisitun: Trinkaus \& Biglari, 2006), at ca. 1,300m, and in Usbekistan (e.g. Teshik-Tash: Okladnikov, 1949), at ca. $1,800 \mathrm{~m}$. No site with Early Neandertals reaches altitudes of $1,000 \mathrm{~m}$. Some alpine sites with Middle Paleolithic artefacts but without human fossils are situated at similar or even higher altitudes, for example: Jiboui (Vercors, 1,620m), Wildenmanlisloch (Appenzell, 1,628m), Chiffon (Vercors), Ramesch-Knochenhöhle (Austrian Alps, 1,960m), and Salzofenhöhle (Austrian Alps, 2,068m) (see Pinhasi et al., 2011); the Armenian cave site Hovk-1 reaches an altitude of 2,040m (Pinhasi et al., 2011). Thus, based on the discussion above we excluded areas above $2,000 \mathrm{~m}$ from our study. The lower elevation limit for the modelling is the present-day sea level, even though there are some find localities that are below sea level (Zeeland Ridges, North Sea/Netherlands: Hublin et al., 2009; Amud Cave, Israel: Valladas et al., 1999). Thus, no bathymetric data were used to characterize the topographic situation during glaciations, when sea levels were lower. The modelled Early and Classic Neandertal sites do, however, show specific spatial distributions of their site probabilities. Generally, the Classic Neandertals show a wider range in the spatial distribution, with a clear preference for steeper areas of mountain ranges. Early Neandertals are characterized by high probabilities in areas of flatter terrain and inter-mountain areas.

Given the predictions provided by the model, both Early and especially Classic Neandertals might have found appropriate living conditions in northern Africa and the Mediterranean islands, as shown in Figures 4 and 5. Nevertheless, up to now no unambiguous Neandertal fossil has been found on the African continent. It is obvious that anatomically-modern humans must have lived in northern Africa when Neandertals moved 'Out of Europe' (Serangeli \& Bolus, 2008; Bolus, 2014). Hence it might be possible that cultural aspects play an important role in the lack of Neandertals in northern Africa and in Africa in general.

The fact that most Neandertal fossils have been discovered in caves may constrain the interpretations given in this paper. Although a considerable number of fossils have been found in open-air sites, regions without caves may be under-represented in the fossil record and consequently also in our models.

The highest degree of accuracy and robustness in terms of the spatial pattern can be expected for the Classic Neandertals $(\mathrm{N}=143)$. The Classic Neandertals are also the best documented of Neandertals. Accordingly, for an external validation we compared the simulated probabilities of the Neandertal sites based on the Neandertal fossil distribution with an external validation set. This external dataset consists of Middle Paleolithic artefact sites $(\mathrm{N}=139)$, most of them being open-air sites. 


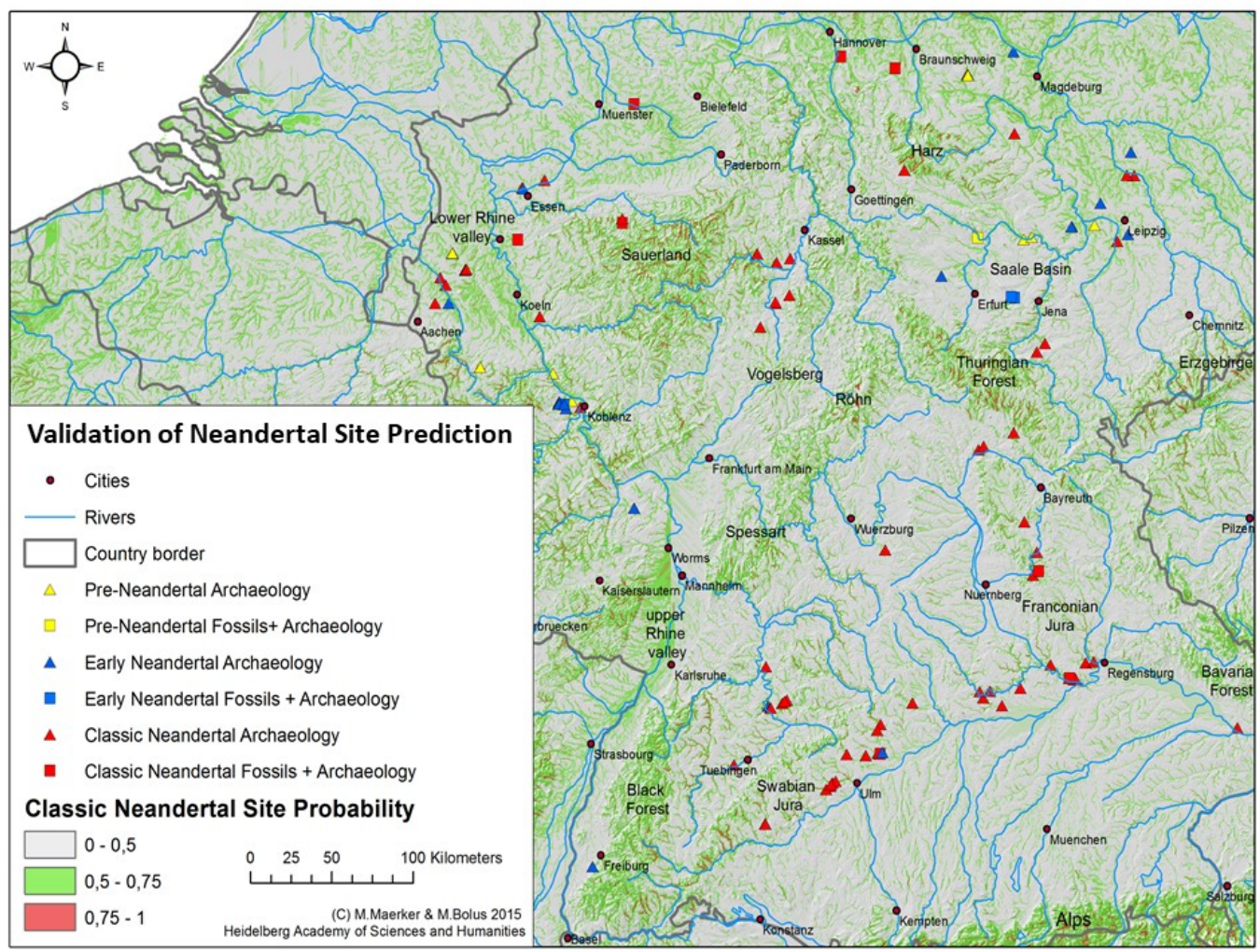

Figure 7: Simulated probabilities for Classic Neandertal site distribution and extemal validation data set consisting of Middle Paleolithic artefact sites in Gemany (data collection: 2014)

Figure 7 shows the predicted probabilities of Classic Neandertal sites based on the fossil record and the distribution of sites with Middle Paleolithic artefacts in Germany. Generally, a very good fit can be observed in terms of the spatial distribution pattern. The model shows medium to high probabilities in the areas where the external dataset has a concentration of sites. In the Swabian Jura, Neckar valley, Franconian Jura, Thuringian Forest, Saale basin, Lower Rhine valley and upper Weser valley especially, there is a good correspondence with the modelled site probabilities.

However, there are also areas where the validation dataset showed no or only weak indications for Neandertal sites, where our model yields medium to high probabilities. This is especially the case for the valleys of the German Mittelgebirge such as the Röhn, Spessart, Sauerland and Erzgebirge valleys, and for the Black Forest. This could indicate that the spatial pattern of the probabilistic model is biased by the high number of cave sites in the Classic Neandertal fossil record and, conversely, by the fact that the validation dataset highlights open-air sites, which do not normally occur along steep valleys. However, both the model and the validation dataset show predominantly sites with a certain relief that would allow Neandertals to hide, protect themselves or observe game, whereas flat areas seem to be the exceptions. Especially in the flat areas southeast of Würzburg, in areas east and southeast 
of the Harz, and in the Saale basin, we documented Classic Neandertal artefact sites, but the stochastic model does not show high probabilities for these regions. One interpretation could be that the sites themselves may not have been deemed suitable on environmental grounds for settling, so perhaps cultural aspects played a major role in favouring these sites. Nonetheless, the site distribution shows a very high correlation to major waterways such as the Danube, Rhine and Elbe and their tributaries.

Finally, we have to stress that our probabilistic model identifies site suitability. This means that a site was potentially suitable for Classic Neandertals but not necessarily that it was occupied by them. Nevertheless, and this can also be seen as a strength of the model, we are able to model site probabilities and thus highlight areas for future archaeological survey.

\section{Conclusions and perspectives}

In this paper, we presented an explorative spatial data analysis of Neandertal fossil sites in Europe and topographic indices for environmental conditions in the areas of the find locations. Hence, the indices can be interpreted as specific preferences that played a role in site selection for different Neandertal groups. To assess these preferences, we applied two different modelling approaches: BRT and MEM. Due to the low number of cases of PreNeandertals $(\mathrm{N}=10)$, they were excluded from the analysis. For Early and Classic Neandertal sites, the models are consistent concerning performance and variable importance, even though BRT outperforms MEM. However, site-selection criteria for Classic Neandertals consider more strategic aspects, whereas Early Neandertal sites seem to be selected mainly on climatic criteria. For Classic and Early Neandertals site selection, both models reveal the high relevance of water resources. Generally, the consistent variable importance results indicate that the models yield distinct and robust information on site-selection criteria, and the models reveal significant differences between the Early and Classic Neandertals siteselection criteria.

The external validation using 139 Middle Paleolithic artefact sites in Germany shows a good fit in terms of the spatial pattern of the site predictions. Nevertheless, in a future project phase, a further validation of our results will be performed using the distribution over a wider geographic area of Middle Paleolithic sites without Neandertal fossils - i.e. the validation dataset will not be limited, as here, to an area such as Germany. Additionally, both Early and Classical Neandertals cover huge temporal ranges, and we will try to refine our analysis by taking into account different and changing climatic periods. Finally, in a future assessment we would like to incorporate further boundary information such as bathymetry, inland ice shield extensions, or supplementary lithological information. Such additional information might be directly incorporated into the stochastic models as predictor variables (e.g. lithology, bathymetry) or could be used as masks to cut off the areas that have very low suitability (e.g. ice shields).

To conclude, this paper shows that, generally, there are differences in site-selection criteria between Early and Classic Neandertals, suggesting the strong influence of environmental constraints. The vicinity to waterways seems to play a major role for all Neandertal classes. Nonetheless, we also reveal that it is not possible to explain the entire distribution of 
Neandertal sites by environmental characteristics and features alone. Site suitability in North Africa and the Mediterranean islands together with the seeming absence of Neandertals from those regions must be explained by expansion barriers, competition with anatomicallymodern humans, or cultural aspects. Consequently, site predictions for anatomically-modern humans based on all sites with fossils from the Middle Paleolithic and Middle Stone Age in Africa are a key for the analysis, comparison and interpretation of site preferences of Neandertals and anatomically-modern humans.

The approach and the algorithms (available as open source) are well documented and can be applied in other areas of research, such as digital soil mapping or species distribution modelling. Hence, the approach is usable for other datasets or similar research questions.

\section{References}

Arsuaga J. L., Martínez I, Arnold L. J., Aranburu A., Gracia-Téllez A., Sharp W. D., Quam R. M., Falguères C., Pantoja-Pérez A., Bischoff J., Poza-Rey E., Parés J.M., Carretero J. M., Demuro M., Lorenzo C., Sala N., Martinón-Torres M., García N., Alcázar de Velasco A., Cuenca-Bescós G., Gómez-Olivencia A., Moreno D., Pablos A., Shen C.-C., Rodríguez L., Ortega A. I., García R, Bonmatí A., Bermúdez de Castro J. M., \& Carbonell E. (2014). Neandertal roots: Cranial and chronological evidence from Sima de los Huesos. Science. 344, 1358-1363.

Beven K. J., \& Kirkby M. J. (1997). A physically-based variable contributing area model of basin hydrology. Hydrology Science Bulletin, 24(1), 43-69.

Böhner J., \& Antonić O. (2009). Land Surface Parameters Specific to Topo-Climatology. In: Hengl, T., Reuter, H.I. (Eds.), Geomorphometry - Concepts, Software, Applications, 33, 195-226.

Böhner J., \& Conrad O.. (2008). SAGA-GIS Module Library Documentation (v2.1.3). Diurnal Anisotropic Heating. http://www.saga-gis.org/saga_module_doc/2.1.3/ta_morphometry_12.html (01.2015).

Böhner J., McCloy K. R., \& Strobl J. (2006). SAGA - Analysis and Modelling Applications. Göttinger Geographische Abhandlungen, pp 115.

Bolus M. (2014). Dispersals of Early Humans: Traces, Frontiers, and New Territories. In: Henke, W., Tattersall, I. (Eds.), Handbook of Paleoanthropology. Second Edition.

Bräuer G. (2008). The Origin of Modern Anatomy: By Speciation or Intraspecific Evolution? Evolutionary Anthropology, 17, 22-37.

Conrad O. (2002). SAGA-GIS Module Library Documentation (v2.1.3). Module vertical distance to river network. 2002; http://www.saga-gis.org/saga_module_doc/2.1.3/ta_channels_3.html (01.2015).

Conrad O. (2003). SAGA-GIS Module Library Documentation (v2.1.3). Module Channel network and drainage basins. 2003; http://www.saga-gis.org/saga_module_doc/2.1.3/ta_channels_5.html (01.2015).

Conrad O. (2006). SAGA - program structure and current state of implementation. Göttinger Geographische Abhandlungen, 115, 39-52.

Dean D., Hublin, J.-J., Holloway R., \& Ziegler R. (1998). On the phylogenetic position of the preNeandertal specimen from Reilingen, Germany. Journal of Human Evolution, 34, 485-508.

Elith J., Leathwick J. R., \& Hastie T. (2008). A working guide to boosted regression trees. Journal of Animal Ecology, 77, 802-813.

Fielding A. H., \& Bell J. F. (1997). A review of methods for the assessment of prediction errors in conservation presence/absence models. Environmental Conservation, 24(1), 38-49. 


\section{Märker \& Bolus}

Freeman G. T. (1991). Calculating catchment area with divergent flow based on a regular grid. Computers and Geosciences, 17, 413-22

Friedman J. H. (1999). Stochastic gradient boosting. Technical Report. Department of Statistics, Stanford University, USA. http://www.salford-systems.com/treenet.html.

Friedman J. H. (2001). Greedy function approximation: a gradient boosting machine. The Annals of Statistics, 29, 1189-1232.

Gomes V. H. F., Ijff S. D., Raes N., Amaral I. L., Salomão R. P., de Souza Coelho Luiz, de Almeida M. F. D., et al. (2018): Species Distribution Modelling: Contrasting presence-only models with plot abundance data. Scientific Reports, 8(1003), 1-12.

Goudie A. S. (2004): Encyclopedia of geomorphology. London, New York: Routledge: International Association of Geomorphologists, 1156pp.

Grimm R., Behrens T., Märker M., \& Elsenbeer H. (2008). Soil organic carbon concentrations and stocks on Barro Colorado Island - Digital Soil Mapping using Random Forest analysis. Geoderma, 146 (1-2), 102-113.

Guisan A., Weiss S. B., \& Weiss A. D. (1999). GLM versus CCA spatial modeling of plant species distribution. Plant Ecology, 143, 107-122.Hanley J. A., \& McNeil B. J. (1982): The meaning and use of the area under a receiver operating characteristic (ROC) curve. Radiology,143(1), 29-36.

Harvati K. (2007). 100 years of Homo beidelbergensis - life and times of a controversial taxon. Mitteilungen der Gesellschaft für Urgeschichte, 16, 85-94.

Hosmer D. W., \& Lemeshow S. (2000). Applied Logistic Regression. 2nd ed., Wiley, New York.

Hublin J.-J. (1998). Climatic changes, paleogeography, and the evolution of the Neandertals. In: Akazawa, T., Aoki, K., Bar-Yosef, O. (Eds.), Neandertals and Modern Humans in Western Asia. New York/London, Plenum Press, 295-310.

Hublin J.-J. Origine et Évolution des Néandertaliens. In: Vandermeersch, B., \& Maureille, B. (2007). Les Néandertaliens. Biologie et cultures. Paris, Editions du CTHS. 95-107.

Hublin J.-J., Weston D., Gunz P., Richards M., Roebroeks W., Glimmerveen J., \& Anthonis L. (2009). Out of the North Sea: the Zeeland Ridges Neandertal. Journal of Human Evolution, 57, 777-785.

Jaynes E. T. (1957). Information theory and statistical mechanics. Physical Review, 106, 620-630.

Manel S., Ceri Williams H., \& Ormerod S.J. (2001). Evaluating presence-absence models in ecology: the need to account for prevalence. Journal of Applied Ecology. 2001, 38, 921-931.

Marchi L., \& Fontana G. D. (2005). GIS morphometric indicators for the analysis of sediment dynamics in mountain basins. Environmental Geology, 48, 218-228.

Martín A., \& Rodríguez J. (1979). Avance al estudio geologico de Cueva Hora. Antropología y Paleoecología Humana, 1, 75-78.

Minasny B., \& McBratney A. B. (2016). Digital soil mapping: A brief history and some lessons. Geoderma, 254, 301-3011.

Moore I. D., Garson R. B., \& Ladson A. R. (1991). Digital terrain modelling: a review of hydrological, geomorphological and biological applications. Hydrological Processes., 5, 3-30.

Nobre A. D., Cuartas L. A., Hodnett M., Rennó C. D., Rodrigues G., Silveira A, Waterloo M., \& Saleska S. (2011). Height Above the Nearest Drainage - a hydrologically relevant new terrain model. Journal of Hydrology, 404, 13-29.

Okladnikov A. P. (1949). Investigations of the Mousterian site and the Neanderthal burial at the Teshik-Tash grotto, South Uzbekistan (Central Asia). In: Gremiatsky, M. A, \& Nesturkh, M. F. (Eds.), Teshik Tash: paleolithic man. Moscow State University, Moscow, 7-85.

Olaya V., \& Conrad O. (2008). Geomorphometry in SAGA. In: Hengl, T., \& Reuter, H.I. (Eds.), Geomorphometry: Concepts, Software, Applications. Elsevier, Amsterdam, 293-308.

Phillips S. J., Anderson R. P., \& Schapire R. E. (2004). A maximum entropy approach to species distribution modeling. In: Proceedings of the Twenty-First International Conference on Machine Learning. Banff, Alberta, Canada, . 
Phillips S. J., \& Dudík M. (2008). Modeling of species distributions with Maxent: new extensions and a comprehensive evaluation. Ecography, 31, 161-175.

Phillips S. J., Dudík M., \& Schapire R. E. (2006). Maximum entropy modeling of species geographic distributions. Ecological Modelling, 190, 231-259.

Phillips S. J., \& Elith J. (2010). ROC plots: calibrating species distribution models with presence-only data. Ecology. 2010, 91, 2476-2484.

Pinhasi R., Gasparian B., Nahapetyan S., Bar-Oz G., Weissbrod L., Bruch A.A., Hovsepyan R., \& Wilkinson K. (2011). Middle Palaeolithic human occupation of the high altitude region of Hovk-1, Armenia. Quaternary Science Reviews, 30, 3846-3857.

Planchon O., \& Darboux F. (2001). A fast, simple and versatile algorithm to fill the depressions of digital elevation models. Catena, 46, 159-176.

Reineking B., \& Schröder B. (2006). Constrain to perform: Regularization of habitat models. Ecological Modelling,193, 675-690.

Rightmire G. P. (1998). Human evolution in the Middle Pleistocene: the role of Homo heidelbergensis. Evolutionary Anthropology, 6, 218-227.

Riley S. J., De Gloria S. D., \& Elliot R. (1999). A Terrain Ruggedness that Quantifies Topographic Heterogeneity. Intermountain Journal of Science, 5, 23-27.

Rodríguez J., Burjachs F., Cuenca-Bescós G., García N., van der Made J., Pérez González A., Blain H.-A., Expósito I., López-García J. M., García Antón M., Allué E., Cáceres I., Huguet R., Mosquera M., Ollé A., Rosell J., Parés J. M., Rodríguez X. P., Díez C., Rofes J., Sala R., Saladié P., Vallverdú J., Bennasar M. L., Blasco R., Bermúdez de Castro J. M., \& Carbonell E. (2011). One million years of cultural evolution in a stable environment at Atapuerca (Burgos, Spain). Quaternary Science Reviews, 30, 1396-1412.

Serangeli J., \& Bolus M. (2008). Out of Europe - The dispersal of a successful European hominin form. Quartär, 55, 83-98.

Swets J. A. (1988). Measuring the accuracy of diagnostic systems. Science, 240, 1285-1293.

Tarini M., Cignoni P., \& Montani C. (2006). Ambient Occlusion and Edge Cueing to Enhance Real Time Molecular Visualization. IEEE Transactions on Visualization and Computer Graphics, 12(5), 1237-1244.

Trinkaus E., \& Biglari F. (2006). Middle Paleolithic Human Remains from Bisitun Cave, Iran. Paléorient, 32(2), 105-111.

Tuffreau A. (1976). Les débuts du paléolithique moyen dans la France septentrionale. Bulletin de la Société prébistorique française, 76, 140-142.

Valladas H., Mercier N., \& Froget L. (1999). TL Dates for the Neanderthal Site of the Amud Cave, Israel. Journal of Archaeological Science, 26, 259-268.

Velichko A., \& Spasskaya I. (2017). Climatic Change and the development of landscapes. In: Shahgedanova M. The physical geography of Northern Eurasia. Oxford University Press, 36-69.

Vogel S., \& Maerker M. Reconstruction of the pre-Eruption AD 79 Paleo-topography and Paleoenvironment of the Sarno River Basin (Italy) using Stratigraphical Core Drillings and Data Mining Technologies. Geomorphology, 115(1-2), 67-77.

Vorpahl P., Elsenbeer H., Märker M., \& Schröder B. (2012). How can statistical models help to determine driving factors of landslides? Ecological Modelling, 239, 27-39.

Yokoyama R., Shirasawa M., \& Pike R. J. (2002). Visualizing Topography by Openness: A New Application of Image Processing to Digital Elevation Models. Photogrammetric Engineering \& Remote Sensing, 68, 257-266.

Zevenbergen L.W., \& Thorne C.R. (1987). Quantitative analysis of land surface topography. Earth Surface Processes and Landforms, 12, 47-56. 